\title{
Establishment of a balance between the development of modern medical technology and social ethics
}

\author{
Jinguo Wang ${ }^{1, \mathrm{a}}$ and $\mathrm{Na}$ Wang $^{2, \mathrm{~b}^{\star}}$ \\ ${ }^{1}$ the First Hospital of Jilin University, Changchun 130021, China; \\ 2 the First Hospital of Jilin University, Changchun 130021, China \\ awangjinguolily@163.com, bwangna080613@163.com
}

Keywords: Balance, modern medical technology, social ethics.

\begin{abstract}
The study analyzes the relationship between the modern medical technology and the social ethics, displays the important influence of the social ethics on modern medical technology. The development of modern medical technologies requires adjusting and reforming of the traditional culture, religion and ethics which aren't adapted to technology development to finally make the modern medical technology well serve our mankind.
\end{abstract}

\section{Introduction}

At present, some traditional cultural ideology, religion, and the old ethical code of ethics has hindered the application and development of modern medical technology better, the development of modern medical technology requirements of adjusting and reforming the traditional culture, religion and ethical norms change can not adapt to technology development. Ethics to meet the needs of the development of medical technology, to control and guide effect, achieve the mutual promotion of both, to finally realize the modern medical technology better serve the purpose of our mankind.

\section{Text}

Human material and spiritual needs is the fundamental driving force of the development of the science and technology.No power can destroy human needs, so there is no any reason can stop the development of science and technology.All kinds of social and cultural phenomenon, including religion, due to its own demand, exert influence on the development of science and technology, can only make a certain part of the development of science and technology development or the other part is not a part of development faster slowly, another part of the development but will not prevent the development of science and technology.And culture, religion and other factors also need to make adjustment and reform to adapt to the needs of the development of science and technology [1].

Because of the economic development level of the development of modern medical technology and the progress of the social ethics final decision role, vigorously develop the economy, promote modern medical technology and the development of dynamic balance of social ethics.

People-oriented modern medical technology with the emergence of high and new medical technology and continuously applied to clinical diagnosis and treatment of many diseases efficiently, it is not negative. However, the development of high and new medical technology and the integration of commodity economy, led to the lack of medical humane spirit, the phenomenon of heavy light care treatment widely, medicine has gradually from save patients' physical and mental pain into pure for the treatment of diseases, endangering the healthy development of modern medicine, this kind of idea is unfavorable to the patient back to health as early as possible. Correctly handle the relationship between diseases and medical technology, to rebuild the humanistic spirit of medicine.

Since the ancient times, people would think the medicine is one of the most cultural tradition of a science, the doctor is the most human occupation." Medical is our dedicated" is the developing direction of social expectations medicine. Hippocrates, said: "medicine is all the technology is the most beautiful and the most noble". Because of the development of medicine and medical technology application is closely related to people's health. Medical technology service object is people, medical 
technology can't ignore people at any time, not from the people. Whether medical development to the molecular level or more micro level, no matter how advanced medical technology, medical equipment, we can't forget the medicine and medical technology should take "human center" [2].

However, the development of medical technology make when doctors give patients, overly dependent on technology, and the lack of humanistic care to patients. Many scholars at home and abroad and the human nature indifference, excessive admiration for modern medical technology, in spite of the medical humanities have extremely profound criticism. Britain's famous historian soup than for famous personage daisaku ikeda and Japanese culture, the authors in the dialogue of the 21st century, the modern medicine ignored the medicine made a sharp criticism of human nature. Pointed out that before the doctor today, he seems to feel that lie on the bed is not people with life, and is a known as the "matter" of the flesh. Modern medicine need adhere to the people-centered, the realization of medical humanity regression [3].

"Medical object is the whole person, must consider the integrity of the people and understand the patient's psychological and emotional, and not just against the disease." Adhere to the people-oriented, make the modern medicine from the emphasis ontechnology, superstition, only think that technology is a universal concept of treatment to also attaches great importance to the patients psychological comprehensive conditioning, is to achieve modern medicine medical humanity regression and reconstruction of the important direction of humanistic spirit of medicine.

Such as in organ transplant patients the survival of life should not only consider when, want to consider the quality of life of postoperative, if remain the suffering of patients, postoperative pain is more and more big, the quality of life more and more low, it is based on people-oriented, and is not a real sense of respect for life.

In medical practice, only pay attention to technology, on the one hand, the treatment of dying patients with excessive medical intervention, and ignore the consideration to the patients psychological feelings, prolong the patient's pain, also caused the limited medical resources waste. Adhere to the people-oriented, from the overall Angle to treat diseases, recover to the person's overall care, away from the sort of person as metaphysical thinking habit of machine parts and reconstruction of medical humanities spirit, it is conducive to the healthy development of medicine.

Confucian culture has a great influence on the modern medical ethics is still. In the face of modern medical technology in the traditional culture of ethical challenges, we should to Confucian culture in the historical limitations of love view, baiban (view, life values are modified, we must stick to the policy of the critical inheritance of marxism and absorbing the essence, discard the dregs. Chinese traditional culture and traditional ethical culture, exist in the historical evolution process of the accumulation of behavior, mental models, values, ethics spirit, etc., as a cultural stereotype, often is beyond time and space. For the traditional analysis, identification, selection and transformation create the new culture of socialism moral tradition. Such as the traditional Confucian concept of passive euthanasia is not good, active euthanasia.

With the development of modern medical science, people should renew the idea, gives life values and love view in Confucianism. New connotation, realizes the concept from the holy life, life quality to the life values change, and it is not only beneficial to the improvement of life quality and the improvement of ecological environment, is also beneficial to social progress and development [4]. Human is the earliest emergence, universal view of the world religion. In a very long period in history, religion is a social has a dominant ideology. Religious due to their need, and accept the new achievements of science and technology, but for the sake of their own interests, and can't exactly accept new achievements of science and technology, it's new science and technology developments are modified to exaggerate or distort after acceptance, the development of science and technology to change religion itself.

With the continuous development of people, is a new scientific discovery may now become the common sense constantly in the development of science and technology and innovation. And the requirements of religious doctrine is stability, the doctrine of changing is not people of faith. Therefore, scientific understanding of mankind, in religion is fixed into a stable dogma. These doctrines due to the stability of the religious doctrine will not be updated with the development of 
science and technology, may along with the development of the people to know and prove to be wrong, thus leading to science and technology and religious conflicts, but inevitably is the victory of science and technology results in the long run. Modern natural science was produced in Europe, the intense conflict between modern science and Christianity. The development of modern medical technology also impacts the Christian doctrine. The existence of religion to its attitude to science and technology determine its own value. In order to adapt to the development of technology, including the development of modern medical technology), religion will sooner or later to adjust their own doctrine. Religious doctrine in order to promote human to the good target, serve for the construction of good social ethics, is the best religion in the present social conditions.

Attaches great importance to the humanistic care of medical technology, to strengthen publicity and education, science, advanced the idea of the people to encourage people to update old ethical concept, promotes the life value theory on the basis of new life ethics, make the development of the technology and application is the purpose of being true.

Traditional medical ethics is a basic principle of theory of divine life, theory of divine life is a kind of performance of obligations and the theory of virtue. It is the basic idea of "life to heavy, expensive in daughter, of a party, more than in the daughter party. Asked the doctor to maintain people's life, unconditionally believe life is absolutely cannot infringe the box. Life is very sacred, no one can be taking the life of themselves and others. No matter under what circumstances, to save life, prolong life is the doctor's bounden duty and responsibility, is the fundamental requirement of medical ethics. And theory of divine life unconditionally against death, even for those inevitable death, is absolutely opposed.

People not only live, but also live happy. Think that a person has the quality of life is dependent on the quality of life. Quality of life of basic moral principles are: respect for human life, and death of the recipients. Respect for human life value is for value and quality of life. And, the theory of the death of the recipient is the basic content of respect for human life. This is the biggest difference between with the theory of divine life.

On the value of life is becoming the dominant idea of modern medical ethics, the modern human control over life and death control the main theoretical basis. The theory is to put the people material life value, spiritual value and human value as measure individual and social benefits of a kind of ethical theory. Is realistic criticism, value consciousness and the moral responsibility of the care for life purpose. Life value is the original theory of divine life and negative criticism and inheritance of the theory of quality of life, namely "revaluation of all values". Is it that life is sacred, divine lies in its value, is by its value to reflect the size, quality of life of the high and low end is also reflected by the size of the sexual life value. Life value into the life of the gradual and dying process are value judgment of life from life's intrinsic value and extrinsic value two aspects to consider. The intrinsic value of the determined by the quality of life of life is the premise and foundation to judge the value of life. And a life for others, the society and the significance of human is the external value of life, it is the purpose of value judgment of life and belonging.

With the application of high and new technology in clinical medicine, can intervene the process of human nature, make the traditional theory of divine life began to shake. Just simply emphasize the sanctity of life, dying patients caused by extreme pain and the practice of a large amount of waste of resources, is not meet the requirements of the moral concept of sustainable development [4]. We break the traditional idea, the scientific outlook on development to meet the development of medical progress and ethical problems. In prolonging life with modern medical technology at the same time, pay attention to the improvement of life quality, achieve the current interests and long-term interests, the unity of the holy life and quality of life, like this only then is advantageous to the medical research progress and the improvement of medical technology.

Strengthen the propaganda on the value of life new life ethics, make more people know the value and significance of life, contribute to achieving the current interests and long-term interests of the medical technology, realize sustainable development.According to the life value theory point of view, euthanasia is moral, because for a patient suffering from illness, to maintain the life has no value and significance, excessive medical treatment can be lengthened meaningless death, pain.So, under 
certain conditions, in order to relieve the pain of not cure patients, for he (she) the practice of euthanasia, the patient painlessly is ethical morality, to die with dignity.

Such as cloning for reproduction, for the treatment of infertility is justified, and meaningful. Because the reproductive technology before for infertile couples needs to rely on donated eggs and sperm to achieve the purpose of fertility, the offspring of that does not have its own genetic traits. And now the application of cloning technologies, can by cloning their DNA to produce offspring. Therefore, cloning technology can solve the problem now facing human birth. Cloning technology may be alienation, however, be some rule, exploitation of others, others to seek personal gain. For example, someone trying to use cloning technology used for organ transplant donor to obtain huge profits, or for their own USES the slave, this kind of practice is the human cloning as a material, and fundamentally the dignity of people, this kind of behavior is immoral.

Therefore, should be against the abuse of the modern medical technology. When applied medical technology can help people improve interests, promote the development of the life, also do not damage the interests of others, the lives of others, is ethical. If application a though medical technology has brought some benefits, at the same time harm the interests of others, or damage to the lives of others, this is not in conformity with the moral, is we are opposed to act. For proper application and development of modern medical technology, to prevent being abused by some people, need to develop certain ethics and the need to strengthen supervision and management. Exercise legal control legislation against surrogate, ban organs such as buying and selling, such as opposed to reproductive cloning and euthanasia. Implement the control of public opinion, play to the function of supervision by public opinion and the establishment of medical ethics committee at all levels to strengthen its function of ethical review, etc.

\section{Summary}

For modern medical technology, should not be used old ideas or the development of the code of ethics to restrict or restrain it, and should be adapted to the development of it, adjusting and reforming the outdated in ethics and ethics, this can not only promote the development of medical technology, and can promote the progress of human culture and morality. Science and technology is the value of the load, the modern medical technology in to human survival health benefits at the same time,

Also caused a lot of ethical questions. Modern medical technology and realize the harmonious development of both social ethics can make medical technology better for the benefit of humanity, and conducive to the development of social ethics.

\section{References}

[1] Lujun Gao, Ling Liu, Jihui Zhang, Lidan Hou. Building of Smart Home Medical System Based on Internet of Things [A]. Proceedings of 2016 Cloud Computing and Internet of Things Conference (CCIOTC2016) [C]. 2016

[2] Xianxiang Chen,Zhen Fang,Ren Ren,Shanhong Xia,Yangmin Qian,Huaiyong Li,Lili Tian,Wenxi Zhai,Weibing Xu,Hui Gao. Simple and efficient baseline removal method for a smartphone based ECG detection device[A]. Proceedings of 2013 International Conference on Future Computer and Information Technology(ICFCIT 2013)[C]. 2013

[3] Fang Qingwei. Research on Evaluation Index System of Management Effectiveness on Hospital Human Resource Based on Balanced Scorecard[A]. Proceedings of 2011 International Conference on Fuzzy Systems and Neural Computing(FSNC 2011 V2)[C]. 2011

[4] Li zhiyi,Pan Ling,Cui Lifang,Xie shiping. Application of big data technology in clinical medicine and scientific research[A]. Proceedings of International Conference on Economics and Management Innovations 2016 (ICEMI 2016)[C]. 2016 